Cite this: Org. Biomol. Chem., 2014, 12, 1211

Received 16th September 2013, Accepted 17th December 2013

DOI: $10.1039 / c 3 o b 41888 j$

www.rsc.org/obc

\section{"Sulfolefin": a mixed sulfinamido-olefin ligand in enantioselective rhodium-catalyzed addition of arylboronic acids to trifluoromethyl ketones $\uparrow$}

\author{
Victoria Valdivia, ${ }^{\mathrm{a}, \mathrm{b}}$ Inmaculada Fernández ${ }^{{ }^{\mathrm{b}}}$ and Noureddine Khiar*a
}

Performing catalytic enantioselective carbon-carbon bond forming reactions, especially for the synthesis of tertiary carbinols, is one of the most challenging goals in modern asymmetric synthesis. Herein, we report an efficient enantioselective catalytic approach for the 1,2-addition of arylboronic acids to trifluoromethyl ketones affording tertiary trifluoromethyl-substituted alcohols with high yields and good enantioselectivities. The reported process uses as a catalyst precursor the shelf stable sulfinamidoolefin ligand 1, "sulfolefin", obtained on a multigram scale and in one step from a sugar derived sulfinate ester.

Fluorinated compounds have found extensive application in the fields of materials, pharmaceuticals and agrochemistry. ${ }^{1}$ Particularly, the syntheses of chiral tertiary trifluoromethylsubstituted alcohols have gained increasing interest due to their unique properties and unusual reactivities. ${ }^{2}$ In this context, numerous methods for the trifluoromethylation of carbonyl compounds have been reported. ${ }^{3}$ However, enantioselective trifluoromethylation is difficult to achieve and good enantiomeric excesses are rarely reached. ${ }^{4}$

An alternative strategy for the syntheses of trifluoromethyl substituted tertiary alcohols would be the addition of boronic acids to trifluoromethyl ketones, due to the ready availability, good stability, and non-toxic nature of various boronic acids as the starting materials. ${ }^{5}$ However, the formation of tetrasubstituted carbons via the addition of carbon nucleophiles to ketones still constitutes a major challenge in synthetic chemistry. ${ }^{6}$ Indeed, only three catalytic enantioselective arylations of fluorinated ketones have been reported, ${ }^{7,8}$ affording

\footnotetext{
${ }^{a}$ Instituto de Investigaciones Químicas, C.S.I.C-Universidad de Sevilla, c/. Américo Vespucio, 49., Isla de la Cartuja, 41092 Sevilla, Spain.E-mail: khiar@iiq.csic.es; Fax: +34954460565 ; Tel: +34954489559

${ }^{b}$ Departamento de Química Orgánica y Farmacéutica, Facultad de Farmacia, Universidad de Sevilla, c/. Profesor García González, 2, 41012 Sevilla, Spain. E-mail: inmaff@us.es; Fax: +34954556737; Tel: +34954555993

$\dagger$ Electronic supplementary information (ESI) available: Experimental procedures for the sulfolefin-Rh-catalyzed 1,2 addition of boronic acids to trifluoromethyl ketones, ${ }^{1} \mathrm{H}$ and ${ }^{13} \mathrm{C}$ spectra and HPLC chromatograms of the adducts $4 \mathbf{4}-\mathbf{4 i}$ are given. See DOI: $10.1039 / \mathrm{c} 3 \mathrm{ob} 41888 \mathrm{j}$
}

trifluoromethylated carbinols with modest yields and ee's in most cases. ${ }^{8}$ The three methods employ P-coordinating ligands, either as a phosphine, phosphite, or phosphoramidite group. Despite their excellent coordinating behavior, P-based ligands which are generally obtained through multistep syntheses suffer moreover from their poor stability toward oxygen, which imposes stringent experimental conditions. In sharp contrast, sulfinyl-based ligands, which have been scarcely used as catalyst precursors, present undeniable advantages for their applications in asymmetric catalysis. ${ }^{9}$ In this sense, sulfinyl derivatives are air, oxygen and moisture stable, and are ideally suited for the construction of diverse metal-ligand complexes with a well-defined chiral environment as a result of the close proximity of the chiral sulfur atom to the coordination sphere of the metal. ${ }^{10}$ Within our interest in the synthesis and applications of chiral sulfur derivatives in organic ${ }^{11}$ and metalpromoted catalysis, ${ }^{12}$ we have recently reported that $C_{2}$-symmetric bis-sulfoxides ${ }^{13}$ and $\mathrm{C}_{1}$ mixed sulfinamido-olefin ligands are good catalyst precursors in Rh-promoted addition of boronic acids to activated alkene and ketones in organic solvents and in water. ${ }^{14}$

Based on these premises, in the present work we report on the utilization of the simple cinnamylsulfinamide $\mathbf{1}$ ligand in the rhodium-catalyzed addition of arylboronic acids to trifluoromethylketones for the asymmetric synthesis of chiral trifluoromethylated tertiary alcohols, Fig. 1.

The addition of $p$-tolylboronic acid $3 \mathbf{a}$ to 2,2,2-trifluoroacetophenone $2 \mathbf{a}$ was used as a model reaction, and we were

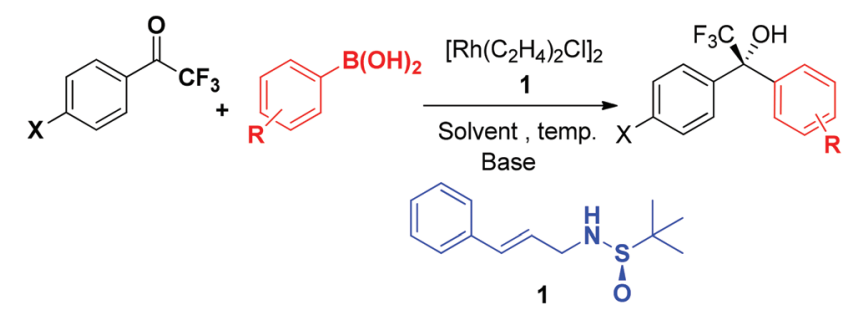

Fig. 1 Rh-catalyzed addition of boronic acids to trifluoromethyl ketones using sulfolefin 1 as a ligand. 
Table 1 Solvent effect on the enantioselective rhodium-catalyzed addition of the arylboronic acids $3 a$ and $3 b$ to the trifluoromethyl ketone $2 a^{a}$

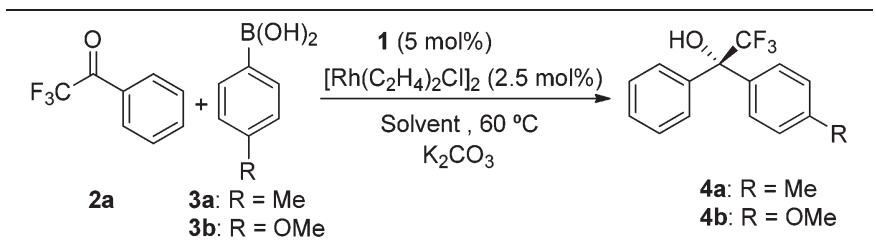

\begin{tabular}{llllcl}
\hline Entry & $\mathrm{R}$ & Solvent & Time $(\mathrm{h})$ & Yield $^{b}(\%)$ & $\operatorname{er}^{c}(\%$ ee $)$ \\
\hline 1 & $\mathrm{Me}$ & TBME & 20 & 27 & $83: 17(66 \%)$ \\
2 & $\mathrm{Me}$ & Dioxane & 20 & 15 & $83: 17(66 \%)$ \\
3 & $\mathrm{Me}$ & $\mathrm{THF}$ & 20 & 0 & - \\
4 & $\mathrm{Me}$ & $\mathrm{Et}_{2} \mathrm{O}$ & 3 & 73 & $84: 16(68 \%)$ \\
5 & $\mathrm{OMe}$ & $\mathrm{Et}_{2} \mathrm{O}$ & 3 & 63 & $85: 15(70 \%)$
\end{tabular}

${ }^{a}$ All reactions were conducted using $5 \mathrm{~mol} \%$ of the ligand together with $2.5 \mathrm{~mol} \%$ of $\left[\mathrm{Rh}\left(\mathrm{C}_{2} \mathrm{H}_{4}\right) \mathrm{Cl}\right]_{2} .{ }^{b}$ Isolated product. ${ }^{c}$ Determined by chiral stationary phase HPLC using a Chiralcel OJ-H® column.

pleased to find that the reaction takes place and provides promising results (Table 1, entries 1-4). Using $\left[\mathrm{Rh}\left(\mathrm{C}_{2} \mathrm{H}_{4}\right) \mathrm{Cl}\right]_{2}$ (2.5 mol\%) as the catalyst precursor and "sulfolefin" 1 ( $5 \mathrm{~mol} \%)$ as the ligand, the addition proceeded at $60{ }^{\circ} \mathrm{C}$ for $20 \mathrm{~h}$ to provide the desired product $\mathbf{4 a}$ in an acceptable ee (66\%), albeit in low yield in TBME described as the best solvent in the three catalytic enantioselective arylations of trifluoromethyl ketones reported to date (entry 1$)^{7,8}$ In an attempt to ameliorate the yield and enantioselectivity of the process, we conducted a study using different ethereal solvents (Table 1, entries 1-4). The use of dioxane (Table 1, entry 2) afforded the product with identical ee $(66 \%)$, but in lower conversion $(15 \%$ isolated yield), while the use of THF (Table 1, entry 3) inhibits the reaction as no trace of the product $\mathbf{4 a}$ was detected in the crude reaction mixture and the starting material was recovered unaltered. Gratifyingly, the use of diethyl ether $\left(\mathrm{Et}_{2} \mathrm{O}\right)$ as the solvent did ameliorate not only the yield $(73 \%)$ and the enantioselectivity ( $68 \%$ ee) but also reduced the reaction time from 20 hours to only 3 hours (Table 1, entry 4). The use of $p$-methoxyphenylboronic acid as a nucleophile afforded the corresponding tertiary trifluoromethyl alcohol $\mathbf{4 b}$ in good yield (65\%) and good ee (70\%), identifying $\mathrm{Et}_{2} \mathrm{O}$ as the most suitable solvent in terms of activity and enantioselectivity for this reaction (Table 1, entry 5).

Next, and in order to unravel the effect of the base on the reaction, various inorganic and organic bases were screened on the addition reaction of 4-methoxyphenylboronic acid $\mathbf{3 b}$ with trifluoroacetophenone 2a (Table 2). The use of potassium phosphate as a base (Table 2, entry 2) afforded the desired product $\mathbf{4 b}$ with acceptable ee (64\%) and modest yield (54\%). Triethylamine afforded the product with enhanced ee $(70 \%)$ but in very low yield (Table 2, entry 3), while no product was formed when using potassium hydroxide as a base (Table 2, entry 4). Satisfyingly, the use of potassium fluoride gave the product in almost quantitative yield (99\%) and with $72 \%$ ee (Table 2, entry 5).
Table 2 Effect of the base on the enantioselective rhodium-catalyzed addition of arylboronic acid $3 b$ to trifluoromethyl ketone $2 a^{a}$

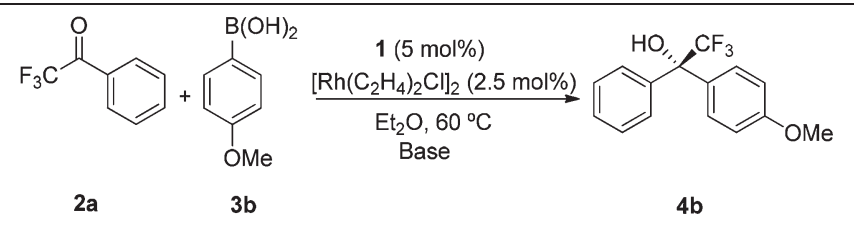

\begin{tabular}{lllr}
\hline Entry & Base & Yield $^{b}(\%)$ & $\operatorname{er}^{c}(\%$ ee $)$ \\
\hline 5 & $\mathrm{~K}_{2} \mathrm{CO}_{3}$ & 63 & $85: 15(70 \%)$ \\
1 & $\mathrm{~K}_{3} \mathrm{PO}_{4}$ & 54 & $82: 18(64 \%)$ \\
2 & $\mathrm{Et}_{3} \mathrm{~N}$ & 12 & $85: 15(70 \%)$ \\
4 & $\mathrm{KOH}$ & - & - \\
5 & $\mathrm{KF}$ & 99 & $85: 15(72 \%)$ \\
&
\end{tabular}

With these results in hand, the scope of the reaction was investigated using boronic acids with varied steric and electronic nature to different trifluoromethyl ketones. As similar enantioselectivities were obtained with potassium carbonate and with potassium fluoride, all condensations were conducted with both bases (Table 3, entries 1-14). Lowering the temperature to $40{ }^{\circ} \mathrm{C}$ leads to the product in very low ee, so the reactions were conducted in $\mathrm{Et}_{2} \mathrm{O}$ at $60{ }^{\circ} \mathrm{C}$. The reaction is dependent on the electronic factors of both boronic acids and ketones. In this sense, boronic acids with electron donating substituents on the aryl group gave the products of addition with good yields (compare entries 1-14). While para-substituted aryls could be introduced with acceptable enantioselectivities and good yields (Table 3, entries 3-6 and 11-14), meta-substituted aryls proceeded with lower ee's and lower yields (Table 3, entries 1-2 and 7-8). Ketone $2 \mathbf{b}$ with a parafluoro substituent (Table 3, entries 3-10) gave the corresponding tertiary trifluoromethylated alcohols in slightly better yields and enantioselectivities than phenyl ketone 2a and ketone 2c with a para-chloro substituent (Table 3, entries 11-14). In the addition of para-tolyl and para-methoxyphenyl groups to ketone $\mathbf{2 b}$, the corresponding tertiary alcohols $\mathbf{4 d}$ and $\mathbf{4} \mathbf{e}$ were obtained with high yields and enantioselectivities of $78 \%$ and $76 \%$, respectively (Table 3, entries 3 and 5). Surprisingly, while in general potassium fluoride gave the final product in higher yield than potassium carbonate, a reversal effect was observed when using the 2-naphthyl boronic acid (Table 3, entries 9 and 10). In this case, the corresponding tertiary alcohol $\mathbf{4 g}$ was obtained with a significant decrease in yield from 99\%, obtained with potassium carbonate (Table 3, entry 9), to $33 \%$ when potassium fluoride was used as a base (Table 3, entry 10).

With regard to the stereochemical outcome of the reaction, one must take into account that ligand $\mathbf{1}$ can coordinate to rhodium in different ways, due to the presence of an alkene function together with various heteroatoms, namely nitrogen, sulfur, and oxygen. Nevertheless, previous NMR studies have 
Table 3 Reaction scope of "sulfolefin"-catalyzed enantioselective rhodium-catalyzed addition of arylboronic acids to trifluoromethyl ketones $^{a}$

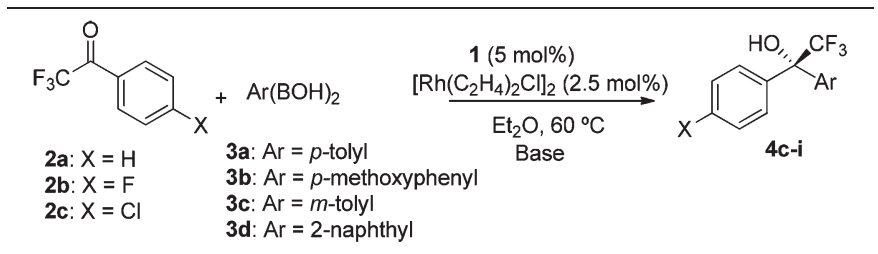

\begin{tabular}{lllll}
\hline Entry & Product & Base & Yield $^{b}(\%)$ & $\mathrm{er}^{c, d}(\%$ ee $)$ \\
\hline 1 & $\mathrm{~K}_{2} \mathrm{CO}_{3}$ & 35 & $78: 22(56 \%)$ \\
& & 99 & $74: 26(48 \%)$
\end{tabular}$$
4
$$<smiles>Cc1ccc(C(O)(c2ccc(F)cc2)C(F)(F)F)cc1</smiles>

$\begin{array}{lll}\mathrm{K}_{2} \mathrm{CO}_{3} & 86 & 89: 11(78 \%) \\ \mathrm{KF} & 64 & 82: 18(64 \%)\end{array}$

5<smiles>COc1ccc(C(O)(c2ccc(F)cc2)c2ccc(F)cc2)cc1</smiles>

$\begin{array}{ll}\mathrm{K}_{2} \mathrm{CO}_{3} & 90 \\ \mathrm{KF} & 93\end{array}$

$88: 12(76 \%)$

6<smiles>Cc1cccc(C(O)(c2ccc(F)cc2)C(F)(F)F)c1</smiles>

$\begin{array}{ll}\mathrm{K}_{2} \mathrm{CO}_{3} & 29 \\ \mathrm{KF} & 40\end{array}$

$83: 17(66 \%)$

$84: 16(68 \%)$

$72: 28(44 \%)$ $75: 25(50 \%)$

10<smiles>OC(c1ccc(F)cc1)(c1ccc2ccccc2c1)C(F)(F)F</smiles>

$\begin{array}{ll}\mathrm{K}_{2} \mathrm{CO}_{3} & 99 \\ \mathrm{KF} & 33\end{array}$

33

$\mathrm{K}_{2} \mathrm{CO}_{3} \quad 58$

$\mathrm{KF} \quad 90$

$\mathrm{K}_{2} \mathrm{CO}_{3} \quad 61$

$\mathrm{KF} \quad 99$

$87: 13(74 \%)$

$82: 18(64 \%)$

${ }^{a}$ All reactions were conducted using $5 \mathrm{~mol} \%$ of the ligand together with $2.5 \mathrm{~mol} \%$ of $\left[\mathrm{Rh}\left(\mathrm{C}_{2} \mathrm{H}_{4}\right) \mathrm{Cl}\right]_{2} .{ }^{b}$ Isolated product. ${ }^{c}$ Determined by chiral stationary phase HPLC using a Chiralcel $\mathrm{OJ}-\mathrm{H}{ }^{\circledR}$ column. ${ }^{d}$ Absolute configurations were determined based on specific rotations. ${ }^{8}$

shown that sulfolefins act as bidentate ligands, coordinating to the rhodium atom through the olefin and the sulfinyl sulfur. ${ }^{14 a}$ Thus, through substrate coordination to the aryl rhodium intermediate in the proposed catalytic cycle of the Rh-catalyzed addition of boronic acid to activated ketone, ${ }^{15}$ two possible intermediates $\mathbf{A}$ and $\mathbf{B}$ can be formed, Fig. 2. While more mechanistic studies are needed, we propose at this stage that owing to the major steric interaction between the aromatic ring of the trifluoromethyl ketone and the tertbutyl group of the ligand, intermediate $\mathbf{A}$ is more favored than B. Consequently, insertion of the aromatic ring in the intermediate $\mathbf{A}$ ( $S i$ face attack), followed by transmetallation, explains the formation of the observed major isomer, Fig. 2.

In summary, the extremely challenging catalytic asymmetric synthesis of trifluoromethyl substituted tertiary alcohols has been realized with good enantioselectivities (up to $79 \%$ ) and high isolated yields (up to 99\%) employing a rhodium/
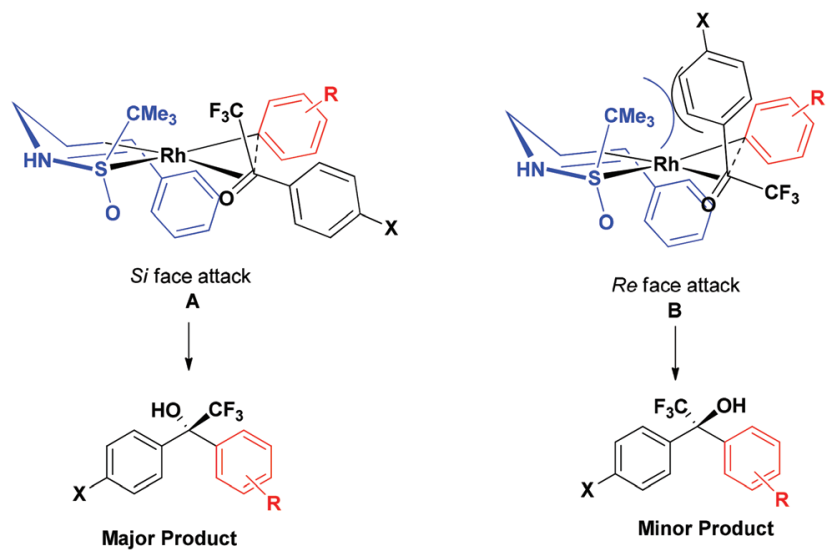

Fig. 2 Proposed model for the stereochemical outcome of the reaction.

"sulfolefin" catalyst. We are currently directing our efforts at enhancing the enantioselectivity of this methodology and its applications for the syntheses of biologically active molecules.

\section{Acknowledgements}

This work was supported by the Ministerio de Economía y Competitividad (grant no. CTQ2010-21755-CO2-00). We acknowledge CITIUS for NMR facilities.

\section{Notes and references}

1 (a) Biomedical Frontiers of Fluorine Chemistry, ed. I. Ojima, J. R. McCarthy and J. T. Welch, ACS Editions, Washington DC, 1996; (b) Organofluorine compounds. Chemistry and Applications, ed. T. Hiyama, Springer, New York, 2000; (c) A. M. Thayer, Chem. Eng. News, 2006, 84, 15.

2 (a) S. E. Denmark and J. Fu, Chem. Rev., 2003, 103, 2763; (b) O. Riant and J. Hannedouche, Org. Biomol. Chem., 2007, 5, 873; (c) P. Tian, H.-Q. Dong and G.-Q. Lin, ACS Catal., 2012, 2, 95.

3 (a) J.-A. Ma and D. Cahard, Chem. Rev., 2008, 108, PR1; (b) S. Mizuta, N. Shibata, S. Akiti, H. Fujimoto, S. Nakamura and T. Toru, Org. Lett., 2007, 9, 3707; (c) H. Kawai, K. Tachi, E. Tokunaga, M. Shiro and N. Shibata, Org. Lett., 2010, 12, 5104.

4 B. R. Langlois, T. Billard and S. Roussel, J. Fluorine Chem., 2005, 126, 173.

5 (a) D. G. Hall, Boronic Acids: Preparation and Applications in Organic Synthesis and Medicine, Wiley-VCH, Weinheim, 2005; (b) R. Shintai, M. Inoue and T. Hayashi, Angew. Chem., Int. Ed., 2006, 45, 3353; (c) H. F. Duan, J.-H. Xie, X.-C. Qiao, L. X. Wang and Q.-L. Zhou, Angew. Chem., Int. Ed., 2008, 47, 4351.

6 (a) Quaternary Stereocenters. Challenges and Solutions for Organic Synthesis, ed. J. Christoffers and A. Baro, WileyVCH, Weinheim, 2005; (b) E. J. Corey and A. Guzman-Perez, Angew. Chem., Int. Ed., 1998, 37, 388; (c) J. Christoffers and 
A. Baro, Adv. Synth. Catal., 2005, 247, 1473; (d) B. M. Trost and C. Jiang, Synthesis, 2006, 369.

7 (a) S. L. X. Martina, R. B. C. Jagt, J. G. de Vries, B. L. Feringa and A. J. Minnaard, Chem. Commun., 2006, 4093; (b) V. R. Jumde, S. Facchetti and A. Iuliano, Tetrahedron: Asymmetry, 2010, 21, 2775.

8 During the preparation of this manuscript Tang's group has reported on the use of P-chiral $C_{2}$ symmetric bis-phosphine in this transformation: R. Luo, K. Li, Y. Hu and W. Tang, Adv. Synth. Catal., 2013, 355, 1297.

9 For an example of palladium-catalyzed, asymmetric intramolecular addition of aryl boronic acids to ketones, see: G. Liu and X. Lu, J. Am. Chem. Soc., 2006, 128, 16504.

10 (a) I. Fernández and N. Khiar, in Organosulfur Chemistry in Asymmetric Synthesis, ed. T. Toru and C. Bolm, WileyVCH-Verlag, Weinheim, 2008, p. 265; (b) I. Fernández and N. Khiar, Chem. Rev., 2003, 103, 3651; (c) B. Delouvrie, L. Fensterbank, F. Najera and M. Malacria, Eur. J. Org. Chem., 2002, 3507.
11 (a) H. B. Kagan and B. Ronan, Rev. Heteroat. Chem., 1992, 7, 92; (b) M. Calligaris and O. Carugo, Coord. Chem. Rev., 1996, 153, 83; (c) E. Alessio, Chem. Rev., 2004, 104, 4203.

12 (a) N. Khiar, F. Alcudia, J.-L. Espartero, L. Rodríguez and I. Fernández, J. Am. Chem. Soc., 2000, 122, 7598; (b) I. Fernández, V. Valdivia, M. Pernia Leal and N. Khiar, Org. Lett., 2007, 9, 2215; (c) I. Fernández, A. Alcudia, B. Gori, V. Valdivia, M. V. García and N. Khiar, Org. Biomol. Chem., 2010, 8, 4388.

13 N. Khiar, A. Salvador, V. Valdivia, A. Chelouan, A. Alcudia, E. Álvarez and I. Fernández, J. Org. Chem., 2013, 78, 651.

14 (a) N. Khiar, A. Salvador, A. Chelouan, A. Alcudia and I. Fernández, Org. Biomol. Chem., 2012, 10, 2366; (b) N. Khiar, V. Valdivia, A. Salvador, A. Chelouan, A. Alcudia and I. Fernández, Adv. Synth. Catal., 2013, 355, 1303.

15 S. Morikawa, K. Michigami and H. Amii, Org. Lett., 2010, 12,2520 . 